\title{
EVALUATION OF SURFACE MICRO-HARDNESS AND FRACTURE TOUGHNESS OF CONVENTIONALLY CONSTRUCTED VERSUS CAD/CAM CONSTRUCTED DENTURE BASE MATERIALS- AN INVITRO STUDY
}

\author{
Maha Nagy Mohamed Kamal *
}

\begin{abstract}
The purpose of the current study was to evaluate surface micro-hardness and fracture toughness of Acetal Resin and Acrylic Resin (PMMA) constructed either by CAD/CAM milling method or by heat polymerized conventional method (lost wax method).

Materials and methods: Twenty-eight specimens (fourteen of each material); Acetal Resin and Acrylic Resin were constructed in the form of discs of $2 \mathrm{~mm}$ thickness and $10 \mathrm{~mm}$ diameter. Discs were divided equally according to the denture base material into two groups, group I for Acetal Resin and group II for Acrylic Resin (PMMA). Each group was subdivided according to the way of construction into; sub-groups $(n=7)$. Sub-groups Ia and IIa for CAD/CAM milled discs and sub-groups Ib, Ilb for conventionally constructed discs. Microhardness was measured on sample surface by digital display Vickers Micro-hardness Tester. Fracture toughness was evaluated by axial loading by the indentation technique.
\end{abstract}

Results: Group I (acetal resin group) recorded statistically significant higher microhardness mean values than group II (acrylic resin group). Moreover, group Ib (injection processed group) recorded statistically significant higher microhardness mean values than group IIb (conventionally processed group). Regarding fracture toughness there was statistically insignificant differences between all groups with higher mean values of group Ia,b (acetal resin groups).

Conclusion: $\mathrm{CAD} / \mathrm{CAM}$ constructed acetal resin and acrylic resin denture base materials presented superior mechanical properties than conventionally constructed ones and expected to be more durable denture bases.

KEYWORDS: CAD/CAM, Acetal Resin. Acrylic Resin, microhardness, fracture toughness.

\footnotetext{
* Lecturer, Removable Prosthodontics Department, Faculty of Dentistry, British University in Egypt (BUE).
} 


\section{INTRODUCTION}

The production and the success of resins in dental field is always considered as a great step of dental materials development. Heat-cured acrylic resin materials was developed firstly in 1940s and has been used in the form of temporary crown and bridge restorations and as denture base material for removable prosthesis as partial and/or complete dentures. Acrylic resin is better known as polymethyl methacrylate (PMMA) and formed mainly of two components including polymethyl methacrylate powder and methyl-methacrylate monomer with a little percentage of crosslinking agent. ${ }^{1}$ Thermal polymerization reaction of PMMA done by conventional lost wax technique method leads to unreacted monomers which cause toxicity, allergic reactions to the oral tissues and lack of resin matrix homogeneous structure, consequently, color changes of the material with weak mechanical properties could be noticed, moreover, thermally polymerized PMMA can results in highly porous material surfaces with increased water sorption properties accompanied with changes in material volume and difficulties in laboratory processing steps. $^{2}$

Due to all this disadvantages, enhancement of polymer industry lead to production of new types of thermoplastic resins alternative to PMMA such as epoxy resins, polyamides (nylons), acetal resins (polyoxymethylene based resin materials), polycarbonate resins, polystyrene etc. ${ }^{3,4,5}$

Since 1986, resins constructed via injection molds have been considered as a replacement of the conventional denture base and direct retainer materials mainly because of its superior esthetic properties. ${ }^{6}$ In the early 1990s, Acetal resin (polyoxymethylene based material POM) has been used to construct all partial denture framework components, denture bases, occlusal splints and implant abutments in addition to tooth colored clasps partial denture. ${ }^{7}$
Acetal resin offers superior esthetic properties in conjunction with more favorable physical and mechanical properties such as strength and flexibility with occlusal wear and fracture resistance, it is capable of restoring vertical dimension during provisional restorative treatment phase. ${ }^{8}{ }^{8}$ However, on the other hand acetal resin lacks the natural color and translucency of thermoplastic resins and polycarbonate resins, it is technique sensitive material and requires special equipments. ${ }^{10,11,12}$

CAD/CAM (Computer-aided design and computer-aided manufacture) milling techniques have been introduced in dentistry for about four decades It can either involve additive manufacturing technique as rapid prototyping or subtractive manufacturing technique using computerized numerical control $[\mathrm{CNC}]$ machine. In prosthodontics, the subtractive procedure (CAD/CAM) is the more commonly used technique and it represents a recent way for designing, milling and constructing dental restorations, partial and/or complete dentures. ${ }^{13}$ There are various advantages of CAD/CAM fabricated dentures over the traditional dentures construction methods; for example: the denture can be designed and fabricated in less than three clinical appointments with accurate occlusal relationship that needs only minimal modifications or adjustments, moreover, the designs of the CAD/CAM constructed dentures can be digitally stored simply and effortlessly so the standardization of clinical researches on edentulism can be guaranteed. ${ }^{14}$

Superior physical and mechanical properties are considered as a dominant factor for the denture base materials to function successfully in the oral environment, denture base cracking or fracture is a commonly seen in the clinics either due to heavy occlusal forces and/or accidental base damage. Moreover, denture fracture may be also due to wrong denture design, improper fabrication method used. ${ }^{15,16}$. Therefore, accurate and precise information are needed to understand the causes of 
denture base fracture and to improve its mechanical properties. So, the purpose of this study was to evaluate micro-hardness $(\mathrm{VH})$ and fracture toughness of Acetal Resin and Acrylic Resin denture base materials constructed with CAD/CAM milling method and compare it with conventionally constructed methods.

\section{MATERIALS AND METHODS}

This study was done using two different materials divided into two groups; Group I used Acetal Resin denture base material which is considered as flexible resin and Group II Acrylic Resin denture base material which is a heat-polymerized type of resin. A total of 28 specimens; 14 specimens were constructed from each group and subdivided into 2 subgroups $a$ and $b \quad(n=7)$ group Ia for $C A D /$ CAM milled Acetal resin specimens, group Ib for Acetal Resin specimens constructed by injection method, group IIa for CAD/CAM milled Acrylic Resin specimens and group IIb for Acrylic Resin specimens constructed by lost wax method.

\section{Specimen fabrication:}

A wax pattern in the form of disc of $2 \mathrm{~mm}$ thickness and $10 \mathrm{~mm}$ diameter was constructed using a silicon mold for standardization.

\section{For groups Ia (CAD/CAM milled Acetal Resin)}

The wax pattern discs were scanned using digital scanner (SHERA eco-scan 7, SHERA WORKSTOFF Technologies, Germany), then the standard tessellation language (STL) files contain the basic milling setting (specimens dimensions) were loaded onto the CAD software (FreeForm; Sensable) and then CAD/ CAM milled from Acetal resin (Bredent, Germany) and acrylic resin blanks (Ivoclar Vivadent Inc. USA) directly inserted in the same 5 axis milling machine (shera eco-mill 5 axis machine, SHERA WORKSTOFF Technologies, Germany). After completion of the milling, the blanks were removed from the machine and the discs were retrieved finished and polished according to manufacturer instructions. Fig 1

\section{Group Ib (injected method Acetal Resin discs)}

Thermoplastic grains of Acetal Resin were heated inside its metallic cartridges then injected into a mold created by the specimen wax pattern, resin was injected by injection molding technique (Thermopress 400, Bredent GmbH \& Co.KG,·Germany) under very high pressure. The resin was plasticized under $220-265^{\circ} \mathrm{C}$ and preheated for $15 \mathrm{~min} .{ }^{17} \mathrm{Fig} .1$

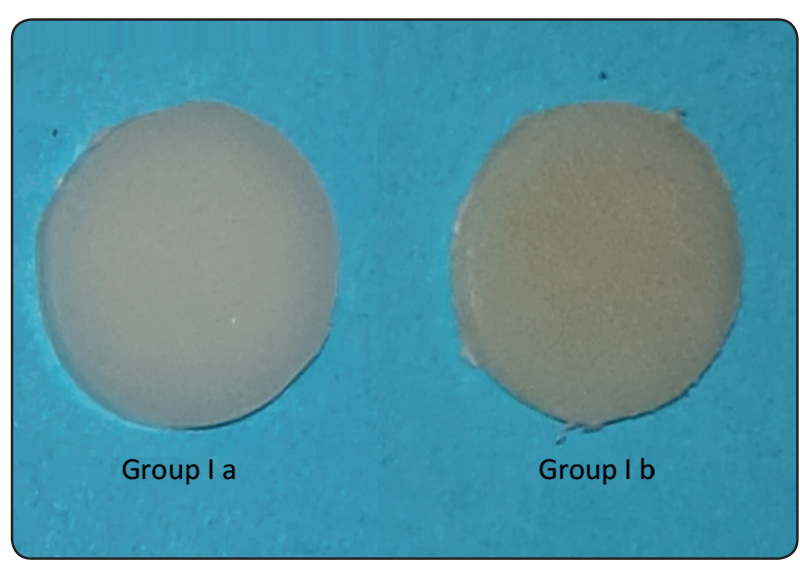

Fig. (1): Sample of acetal resin specimens (group I)

\section{Group IIa (CAD/CAM milled Acrylic Resin)}

Acrylic resin blanks (Ivoclar Vivadent Inc. USA) were used as in group Ia. Fig. 2

\section{Group IIb (lost wax method acrylic resin discs)}

Similarly, A wax pattern in the form of disc of the same dimensions ( $2 \mathrm{~mm}$ thickness and $10 \mathrm{~mm}$ diameter) was constructed from the previously mentioned silicon mold and flasked into the metal curing flask. After wax elimination procedure, the heat-cured acrylic resin (acrostone, Egypt) was mixed, packed and processed. When the polymerization cycle finished, the flasks were bench cooled, then all acrylic specimens were deflasked, finished and polished according to manufacturer instructions. Fig. 2 


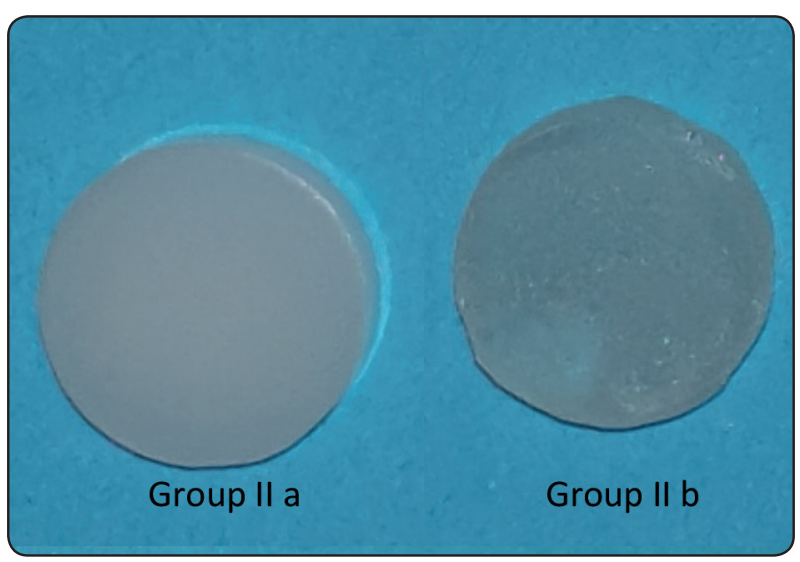

Fig. (2): Sample of acrylic resin specimens (group II)

\section{Testing Procedures}

\section{Surface Micro-hardness:}

Surface Micro-hardness of all the specimens was measured by a device called digital display Vickers Micro-hardness Tester (Model HVS-50, Laizhou Huayin Testing Instrument Co., Ltd. China) with a Vickers diamond indenter and a 20X objective lens. Fig. 3

A $19.6 \mathrm{~N}$ load was used to the specimens surface for about 20 seconds long. Three indentations were made on each specimen surface, the indentations should be away from each other by about $0.5 \mathrm{~mm}$ or more and placed on equal distances. Fig.4,5,6,7

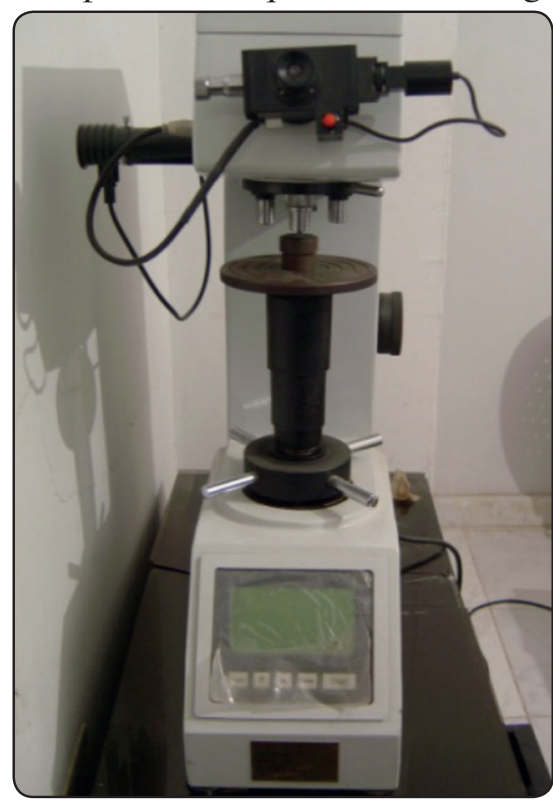

Fig. (3): Vickers Micro-hardness Tester

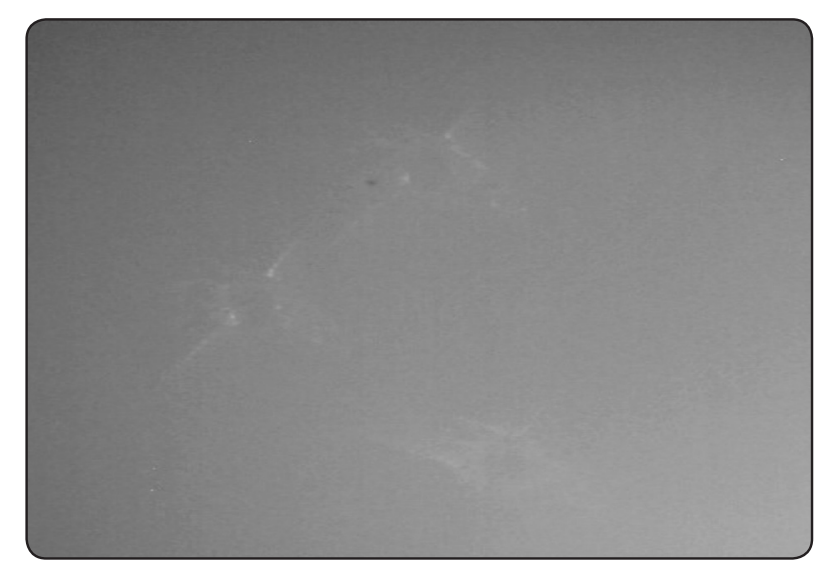

Fig. (4): Indentations in group Ia

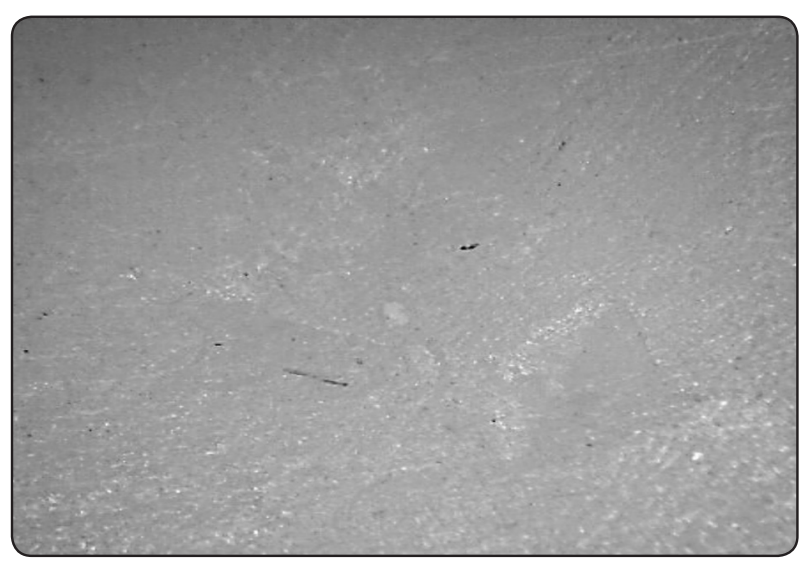

Fig. (5): Indentations in group Ib

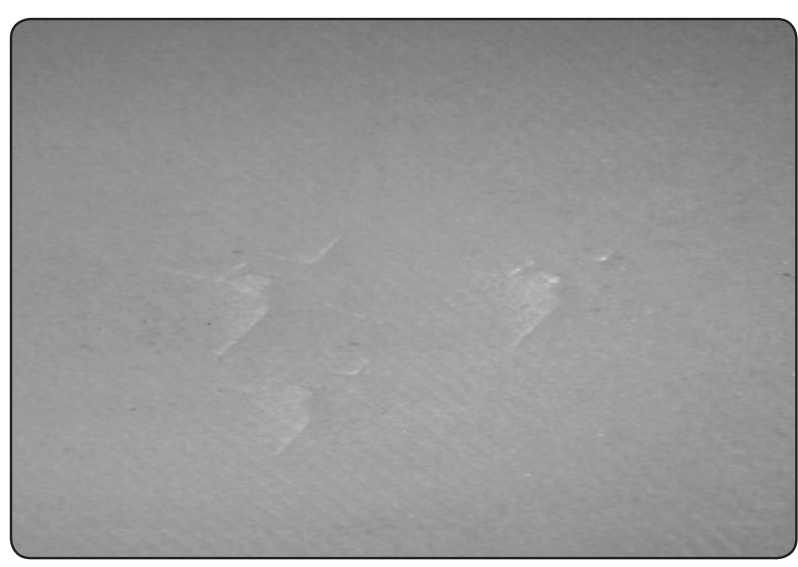

Fig. (6): Indentations in group IIa 


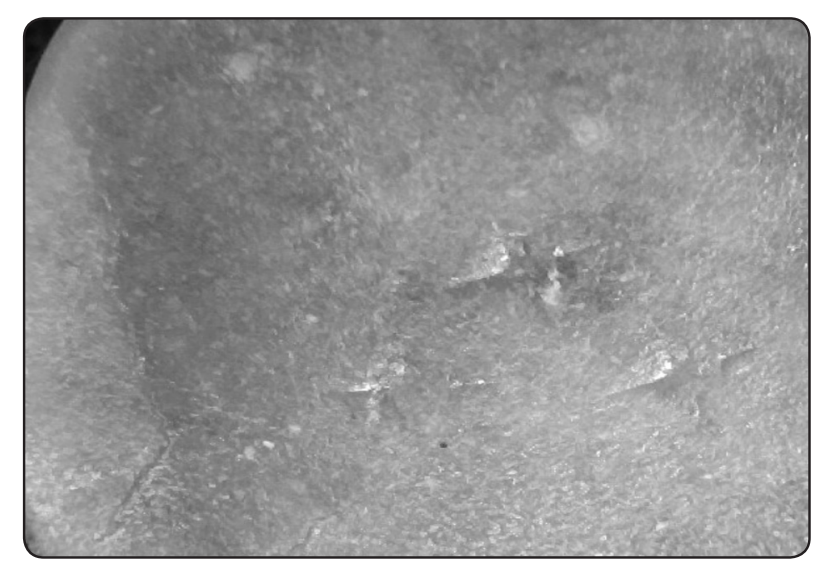

Fig. (7): Indentations in group IIb.

Built in scaled microscope was used to measure the indentations diagonal length, then Vickers values were turned into micro-hardness values through the following equation: $\mathbf{H V}=\mathbf{1 . 8 5 4} \mathbf{P} / \mathbf{d} 2$

where, $\mathbf{H V}$ is Vickers hardness in $\mathrm{Kgf} / \mathrm{mm} 2, \mathbf{P}$ is the load in $\mathrm{Kgf}$ and $\mathbf{d}$ is the length of the diagonals in $\mathrm{mm}$

\section{Fracture toughness measurement:}

The indentation technique used to determine and measure the fracture toughness depends on the formation of a series of cracks around the Vickers diamond indenter. The cracks appear to be emitted from the indentation corners. The length of these cracks " $c$ " increased with an increasing the indentation load and is inversely proportional with the fracture toughness.

The fracture toughness was calculated with the following formula: $\mathrm{KIC}=0.016(\mathrm{E} / \mathrm{H}) 0.5(\mathrm{P} / \mathrm{c} 1.5)$. Where KIC is the fracture toughness, $\mathbf{c}$ is the crack length (measured from the indentation center), $\mathbf{P}$ is the load, $\mathbf{H}$ is the Vickers hardness and $\mathbf{E}$ is the elastic modulus. ${ }^{18}$

\section{RESULTS}

The results were analyzed using Graph Pad Instat (Graph Pad, Inc.) software for windows. A value of $\mathrm{P} \leq 0.05$ was considered statistically significant with the satisfactory level of power set at $80 \%$ and a $95 \%$ confidence level. Continuous variables were expressed as the mean and standard deviation. After homogeneity of variance and normal distribution of errors had been confirmed, two-way analysis of variance ANOVA was performed. One-way ANOVA was done for compared subgroups followed by student t-test.

\section{Microhardness}

Descriptive statistics of microhardness test results measured in (HV) showing mean values and standard deviation for all materials as function of processing technique are summarized in table (1) and graphically drawn in figure (8).

Regardless the processing method, it was found that group I (acetal resin group) recorded statistically significant higher microhardness mean values than group II (acrylic resin group). $\mathrm{p}=<0.0001<0.05$ indicated by two-way ANOVA.

Irrespective of material group, $\mathrm{CAD} / \mathrm{CAM}$ milled groups (Ia, IIa) showed no statistically significant differences with higher microhardness mean value of group Ia (acetal group), it was also found that, group Ib ( injection processed group) recorded statistically significant higher mean values than group IIb (conventionally processed group) $(\mathrm{p}=<0.0001<0.05)$.

TABLE (1) Microhardness test results (Mean \pm SD) for all materials as function of processing technique

\begin{tabular}{|c|c|c|c|c|}
\hline \multirow{2}{*}{\multicolumn{2}{|c|}{ Variables }} & \multicolumn{2}{|c|}{ Statistics } & \multirow{2}{*}{$\frac{\text { t-test }}{P \text { value }}$} \\
\hline & & Mean & $S D$ & \\
\hline \multirow{2}{*}{$\begin{array}{c}\text { Group I } \\
\text { Acetal }\end{array}$} & $\begin{array}{c}\text { Group Ia } \\
\text { Milled }\end{array}$ & 59.762 & 1.1504 & \multirow{2}{*}{$0.2852 \mathrm{~ns}$} \\
\hline & $\begin{array}{l}\text { Group Ib } \\
\text { Injection }\end{array}$ & $58.636^{*}$ & 2.115 & \\
\hline \multirow{2}{*}{$\begin{array}{c}\text { Group II } \\
\text { Acrylic }\end{array}$} & $\begin{array}{c}\text { Group IIa } \\
\text { Milled }\end{array}$ & 50.560 & 1.224 & \multirow{2}{*}{$0.0002 *$} \\
\hline & $\begin{array}{c}\text { Group IIb } \\
\text { conventional }\end{array}$ & $46.807 *$ & 1.293 & \\
\hline P value & & \multicolumn{2}{|c|}{$0.0002 *$} & \\
\hline
\end{tabular}

ns; non-significant $(P>0.05) *$; significant $(P<0.05)$. 


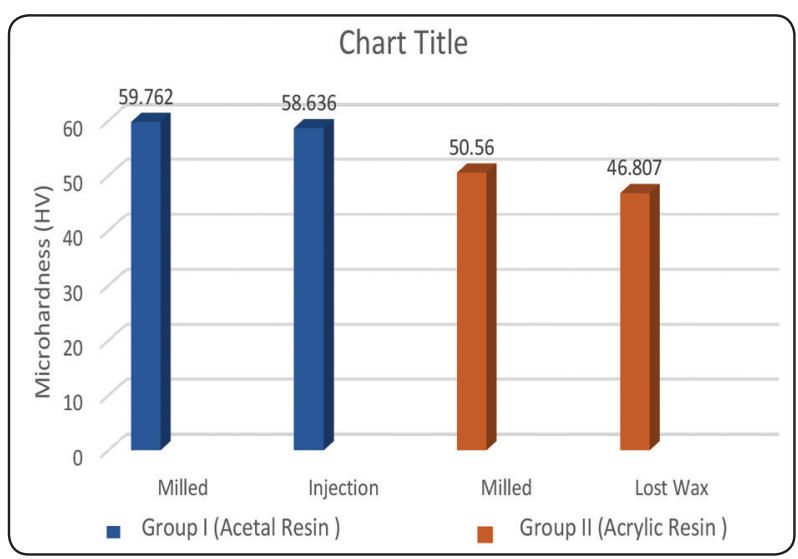

Fig. (8) Column chart showing the mean values of microhardness for all materials as function of processing technique

\section{Fracture toughness}

Descriptive statistics of fracture toughness test results measured in $\left(\mathrm{MPa} . \mathrm{m}^{0.5}\right)$ showing mean values and standard deviation for all materials as function of processing technique are summarized in table (2) and graphically drawn in figure (9).

TABLE (2) Fracture toughness test results $($ Mean \pm SD) for all materials as function of processing technique

\begin{tabular}{|c|c|c|c|c|}
\hline \multirow{2}{*}{\multicolumn{2}{|c|}{ Variables }} & \multicolumn{2}{|c|}{ Statistics } & \multirow{2}{*}{$\frac{\text { t-test }}{P \text { value }}$} \\
\hline & & Mean & $S D$ & \\
\hline \multirow{4}{*}{$\begin{array}{c}\text { Group I } \\
\text { Acetal }\end{array}$} & Group Ia & & & \multirow{4}{*}{$0.1640 \mathrm{~ns}$} \\
\hline & Milled & 4.5377 & 0.56 & \\
\hline & Group Ib & & & \\
\hline & Injection & 3.9277 & 0.6 & \\
\hline \multirow{3}{*}{$\begin{array}{l}\text { GroupII } \\
\text { Acrylic }\end{array}$} & Group IIa & & & \multirow{3}{*}{$0.1184 \mathrm{~ns}$} \\
\hline & Milled & 4.1836 & 0.95 & \\
\hline & $\begin{array}{c}\text { Group IIb } \\
\text { conventional }\end{array}$ & 3.5249 & 0.5 & \\
\hline$P$ value & & \multicolumn{2}{|c|}{$0.1077 \mathrm{~ns}$} & \\
\hline
\end{tabular}

ns; non-significant $(P>0.05) \quad$ *; significant $(P<0.05)$

Regardless the processing method, it was found that group I (acetal resin group) recorded statistically in-significant higher fracture toughness mean values than group II (acrylic resin group) $\mathrm{p}=0.1 .07$ as indicated by two-way ANOVA.

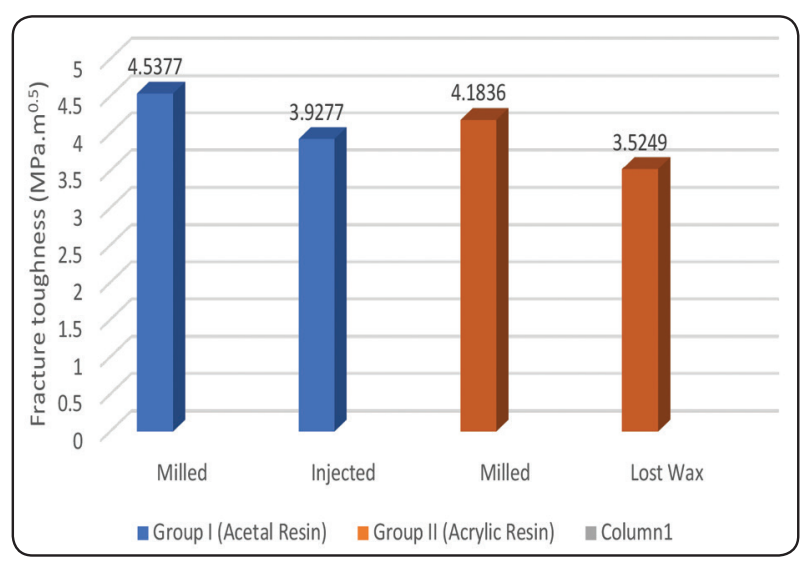

Fig. (9) Column chart showing the mean values of fracture toughness for all materials as function of processing technique.

Irrespective of material group, $\mathrm{CAD} / \mathrm{CAM}$ milled groups (Ia, IIa) showed no statistically significant differences with higher fracture toughness mean value of group Ia (acetal resin group). It was also found that, group $\mathrm{Ib}$ (injection processed group) recorded statistically in-significant higher fracture toughness mean values than conventional processed group $(\mathrm{p}=0.1077<0.05)$.

\section{DISCUSSION}

In this laboratory study, methods of denture base construction and material composition and its role played on the final restoration mechanical and physical properties was evaluated by determining the microhardness and fracture toughness of acetal resin and acrylic resin denture base materials. The results showed significant higher surface hardness of Resin groups constructed by CAD/CAM milling technique than the resin groups constructed by conventional heat-polymerization technique, which might be due to the lower residual monomers content in CAD/CAM milled blocks. Many studies declared that acrylic resin denture bases which milled from blocks that have been polymerized under special condition of high pressure and elevated temperature values showed better surface properties compared to the conventionally constructed ones as the 
elevated pressure helps greatly in long polymer chains formation and consequently higher amount of monomer conversion with less residual monomer presence. ${ }^{19,20,21}$

Another study confirmed that, different methods used for curing heat-polymerized resins seemed to have similar monomer conversion degrees, however, the use of higher pressure for longer periods of time bring a noticeable effect in increasing the monomer conversion into polymer. ${ }^{22}$

In a study done to compare surface properties between conventional heat-polymerized and two new brands of pre-polymerized resin blocks used for CAD/CAM milling of complete denture, it was shown that, CAD/CAM Acrylic Resin demonstrated obviously better material surface properties including hardness and roughness, this may be related to the different way of construction of the CAD/CAM Acrylic Resin blocks which include elevated temperatures and pressure values used its polymerization than the conventional heatpolymerized ones. ${ }^{23,24}$

Results of current study also showed that injection processed group recorded statistically significant higher mean values than conventionally processed group, this result goes with several other studies that revealed that injection molding techniques result in superiorly adapted and dimensionally accurate denture bases compared to the conventional techniques of fabrication. ${ }^{25,26}$

The advantages of injection technique used in the present study were that the resin is delivered in a cartridge which reduces the errors results from improper powder/liquid ratio used, reduced of dimensional changes and helps in shape stability, as well as guarantee high physical and mechanical properties. ${ }^{27}$

It was also found that injection method of processing showed higher microhardness and fracture toughness than conventional method of processing, this was also confirmed in 2012 with a study done by Farina et al, which reported that homogenous elevation of heating temprature of Acrylic Resin resulted in more monomer conversion into polymer, with less plasticizing effect of the residual monomers, and consequently superior surface hardness properties. ${ }^{28}$

It was proved that residual monomers had hazardous effects and considered as a plasticizer which inferiorly affects the mechanical and the physical properties of the resin materials, also unreacted monomers trapped in and got surrounded by the formed polymer network and result in reduction of material clinical longevity and survivability. ${ }^{29}$

It is well known that fracture toughness represents the resistance to cracking of the material. In this study, it was found that acetal resin groups recorded higher fracture toughness mean values compared to acrylic resin groups. This might be due to the high crystallinity nature of the acetal resin material structure (acetal resin (POM) is a semi-crystalline, thermoplastic polymer with high degrees of crystallinity) ${ }^{30}$ which promote superior material mechanical and physical properties such as the hardness; the higher crystallinity structure present of the plastic, the harder and tougher it will be. ${ }^{31}$

this was proven by many other studies that the higher filler loading with wide distribution resulted in superior fracture toughness that can be reached a threshold value of $\sim 55$ to $57 \%$ filler loading. Moreover, fillers with higher volume showed superior surface hardness, compressive strength and also increased modules of elasticity. ${ }^{32,33,34}$

In a study conducted to evaluate the value of adding ceramic fillers to PMMA denture base material and its effect on the material properties such as impact strength, the surface hardness and the fracture toughness of the resin, it was revealed that, the fracture surface of the PMMA without filler added showed of brittle fracture manner forming rapid cracks with sharp edges features, however, 
the manner ductile cracks formation were more obvious in the PMMA group with filles added, it could be concluded that, fracture resistance of heatpolymerized PMMA denture resin showed higher values after fillers addition. ${ }^{35,36}$

\section{CONCLUSION}

Within the limitation of this study it can be concluded that;

1- The method of construction of denture bases material had significant effect on its mechanical properties.

2- $\mathrm{CAD} / \mathrm{CAM}$ constructed acetal resin and acrylic resin denture base materials presented superior mechanical properties than conventionally constructed ones.

3- Acetal resin groups showed higher microhardness and fracture toughness mean values than acrylic resin groups.

\section{REFERENCES}

1. Andreas Faltermeier, Martin Rosentritt, and Dieter Müssig. Acrylic removable appliances: Comparative evaluation of different postpolymerization Methods. Am J Orthod Dentofacial Orthop 2007;131:(3).16-22.

2. Meda Negrutiu, Cosmin Sinescu, Mihai Romanu, Daniela Pop, Sorin Lakatos. Thermo plastic Re sin s for Flexible Frame work Removable Partial Dentures TMJ 2005;55(3):295-299.

3. Ardelean L, Bortun C, Motoc M. Metal-free Removable Partial Dentures made of a Thermoplastic Acetal Resin and Two Polyamide Resins. Materiale Plastice. 2007. 44(4).345-348.

4. Ardelean L., Bortun C, Motoc M. Metal-free removable partial dentures made of a thermoplastic acetal resin and two polyamide resins, Mat. Plast. 2007; 44 (4): 345-355.

5. Pacurar M, Bechir ES, Suciu M, Bechir A, Biris C, Mola FC, Gioga CH, Dascalu IT, Ormenisan A. The Benefits of Polyether-Ether-Ketone Polymers in Partial Edentulous Patients. MATERIALE PLASTICE 2016; 53(4). http:// www.revmaterialeplastice.ro
6. K. Lekha, N. P. Savitha, Meshramkar Roseline, Ramesh K. Nadiger. Acetal resin as an esthetic clasp material Journal of Interdisciplinary Dentistry / Jan-Apr 2012 / Vol-2 / Issue-1 11-14

7. Negruţiu M, Bratu D, Romînu M, et al. Polimeri utilizaţi în tehnologia protezelor mobile şi mobilizabile. Revista Natională de Stomatologie 2001; 4(1):30-41.

8. Negrutiu M, Sinescu C, Romanu M, Pop D, Lakatos S. Thermo plastic Resins for Flexible Frame work Removable Partial Dentures. TMJ 2005;55:295-299.

9. Phoenix RD, Mansueto MA, Ackerman NA, Jones RE. Evaluation of mechanical and thermal properties of commonly used denture base resins. J Prosthodont 2004; $13: 17-27$

10. Yunus N, Rashid AA, Axmi LL, Abu-Hassan MI. Some flexural properties of nylon denture base polymer. J Oral Rahabil. 2005 Jan;32(1):65- 71.

11. Turbush SK, Turkyilmaz I. Accuracy of three different types of stereolithographic surgical guide in implant placement: an in vitro study. J Prosthet Dent. 2012;108:181-188.

12. Mandelaris GA, Rosenfeld AL, King SD, Nevins ML. Computer-guided implant dentistry for precise implant placement: combining specialized stereolithographically generated drilling guides and surgical implant instrumentation. Int J Periodontics Restorative Dent 2010; 30:275-81.

13. Hongqiang Ye, Xinxin Li, Guanbo Wang, Jing Kang, Yushu Liu, Yuchun Sun and Yongsheng Zhou. A Novel Computer-Aided Design/Computer-Assisted Manufacture Method for One-Piece Removable Partial Denture and Evaluation of Fit Int J Prosthodont 2018;31:149-151.

14. Avinash S. Bidra, Thomas D. Taylor and John R. Agar. Computer-aided technology for fabricating complete dentures: Systematic review of historical background, current status, and future perspectives. J Prosthet Dent 2013;109:361-366.

15. Ahmed Omran Alhareb, Hazizan Md Akil, Zainal Arifin Ahmad. Impact strength, fracture toughness and hardness improvement of PMMA denture base through addition of nitrile rubber/ceramic fillers. Saudi J Dent Res. 2017; 8: 26-34.

16. Hae-Hyoung LEE, Chung-Jae LEE and Kenzo ASAOKA . Correlation in the mechanical properties of acrylic denture base resins. Dent Mater J 2012; 31(1): 157-164. 
17. Mekkawy MA, Hussein LA, Alsharawy MA. Comparative study of surface roughness between polyamide, thermoplastic polymethyl methacrylate and acetal resins flexible denture base materials before and after polishing. Life Sci J 2015;12(10):90-95.

18. Fahmy NZ, El Guindy J and Zamzam M. Effect of Artificial Saliva Storage on Microhardness and Fracture Toughness of a Hydrothermal Glass-Ceramic. J Prosthodon. 2009; 18:324-331

19. Infante L, Yilmaz B, McGlumphy E, Finger I. Fabricating complete dentures with CAD/CAM technology. J Prosthet Dent 2014; 111: 351-355

20. Murakami N, Wakabayashi N, Matsushima R, Kishida A, Igarashi Y. Effect of high-pressure polymerization on mechanical properties of PMMA denture base resin. J Mech Behav Biomed Mater 2013; 20: 98-104.

21. Patricia-Anca Steinmassl, Verena Wiedemair, Christian Huck, Florian Klaunzer, Otto Steinmass1, Ingrid Grunert and Herbert Dumfahrt. Do CAD/CAM dentures really release less monomer than conventional dentures? Clin Oral Invest. 2017;21:1697-1705.

22. Lung CY, Darvell BW. Minimization of the inevitable residual monomer in denture base acrylic. Dental materials: official publication of the Academy of Dental Materials. 2005; 21:1119-1128.

23. Cortés-Sandoval G, Martínez-Castãń on GA, PatiñoMarín N, et al: Surface roughness and hardness evaluation of some base metal alloys and denture base acrylics used for oral rehabilitation. Mater Lett 2015; 144: 100-105

24. Al-Dwairi Z, Kawkab Y. Tahboub, Nadim Z. Baba, Goodacre $\mathrm{CH}$ J and Ozcan.M. A Comparison of the Surface Properties of CAD/CAM and Conventional Polymethylmethacrylate (PMMA). J Prosthodont. 2019; 28: 452-457.

25. Parvizi A. Lindquist T. Schneider R. Williamson D. Boyer D. Dawson DV. Comparison of thedimensional accurancy of injection-molded denture base materials to that of conventional pressure-pack acrylic resin. J Prosthodont. 2004; 13(2):83-89.

26. Ganzarolli SM, de Mello JA, Shinkai RS, Del Bel Cury. Internal adaptation and some physical properties of methacrylate-based denture base resins polymerized by different techniques. J Biomed Mater Res B Appl Biomater. 2007;82:169-73.
27. Ardelean L, Bortun C, Motoc M. Metal-free removable partial dentures made of a thermoplastic resin and two polyamide resin. Matriale Plastice. 2007; 44(4): 345-8.

28. Farina AP, Cecchin D, Soares RG, et al: Evaluation of Vickers hardness of different types of acrylic denture base resins with and without glass fibre reinforcement. Gerodontology 2012;29:155-160.

29. Marioara Moldovan 1, Robert Balazsi 2, Andrada Soanca 3, Alexandra Roman 3, Codruta Sarosi 1,* , Doina Prodan 1, Mihaela Vlassa 1, Ileana Cojocaru 4, Vicentiu Saceleanu and Ioan Cristescu. Evaluation of the Degree of Conversion, Residual Monomers and Mechanical Properties of Some Light-Cured Dental Resin Composites. Materials 2019, 12, 2109-2123.

30. Berer M, Halb M, Feuchter M, Pacher G and Pinter G. Fatigue Fracture Properties and Morphology of Polyoxymethylene (POM) Plates Produced under Moderate Processing Conditions. Int J Polymer Science. 2018:1-18.

31. Mekkawy MA, Hussein LA, Alsharawy MA. Comparative study of surface roughness between polyamide, thermoplastic polymethyl methacrylate and acetal resins flexible denture base materials before and after polishing. Life Sci J 2015;12(10):90-95.

32. Sabbagh, J.; Ryelandt, L.; Bachérius, L.; Biebuyck, J.J.; Vreven, J.; Lambrechts, P.; Leloup, G. Characterization of the inorganic fraction of resin composites. J. Oral Rehabil. 2004, 31, 1090-1101.

33. Bayne SC, Heymann HO, Swift EJ Jr. Update on dental composite restorations. J Am Dent Assoc 1994; 125: 687-701.

34. Ilie N, Hickel R, Valceanu AS, Huth KC. Fracture toughness of dental restorative materials. Clin Oral Investig 2012; 16:489-498.

35. Ahmed Omran Alhareb, Hazizan Md Akil, Zainal Arifin Ahmad. Impact strength, fracture toughness and hardness improvement of PMMA denture base through addition of nitrile rubber/ceramic fillers. Saudi J Dent Res. 2017; 8: 26-34.

36. M.R. Ayatollahi, M.R.M. Aliha and M.M. Hassani. Mixed mode brittle fracture in PMMA - An experimental study using SCB specimens. Materials Science and Engineering. 2006; 417: 348-356. 